Jessica Laurance, Riris Loisa: Komunikasi Interpersonal Antara Kakak dengan Adik Kandung Berkebutuhan Khusus (Studi Kasus pada Kakak yang Mempunyai Adik Kandung Penyandang Autisme)

\title{
Komunikasi Interpersonal Antara Kakak dengan Adik Kandung Berkebutuhan Khusus (Studi Kasus pada Kakak yang Mempunyai Adik Kandung Penyandang Autisme)
}

\author{
Jessica Laurance, Riris Loisa \\ jessica.915160031@stu.untar.ac.id,ririsl@fikom.untar.ac.id
}

Fakultas Ilmu Komunikasi Universitas Tarumanagara

\begin{abstract}
Basically, every family hopes to have family members healthy both physically and spiritually. That is not merely the hope of every parent, but a child who becomes a sister or a brother will also expect the same thing. However, some families were blessed with a family member who has special needs. This study aims to investigate how interpersonal communication is established between siblings whom one of them is blessed with special needs. The main theory of this study is interpersonal communication theory which is supported by relational dialectics theory and affection exchange theory. The researcher used a descriptive qualitative approach and case study methods. The data was processed and analyzed according to the coding methods. The criteria for the selection of an informant are an older sibling who has a younger sibling with special needs that lives in the same house. The result of this study indicates that interpersonal communication is established by communicating face-to-face without medium, oldest siblings communicate by adjusting to the special needs of the younger siblings, younger siblings tend to communicate in the form of nonverbal communication, each informant experienced relational dialectics, and an exchange of affection is still possible.
\end{abstract}

Keywords: interpersonal communication, people with autism, relational dialectics, special needs.

\section{Abstrak}

Pada dasarnya setiap keluarga berharap memiliki anggota keluarga yang sehat secara jasmani maupun rohani. Hal tersebut tidak hanya semata-mata harapan setiap orang tua saja, melainkan seorang anak yang menjadi kakak juga mengharapkan kehadiran adik yang sehat secara jasmani maupun rohani. Namun kenyataannya beberapa keluarga dianugerahi anggota keluarga yang berkebutuhan khusus. Rumusan masalah dalam penelitian ini adalah bagaimana komunikasi interpersonal yang terjalin antara kakak dengan adik kandung yang berkebutuhan khusus. Teori utama penelitian ini yaitu teori komunikasi antarpribadi yang didukung dengan teori dialektika relasional dan teori pertukaran kasih sayang. Peneliti menggunakan pendekatan kualitatif yang bersifat deskriptif dan metode studi kasus. Teknik pengolahan dan analisis data adalah dengan pengodean. Kriteria pemilihan informan yaitu seorang kakak yang mempunyai adik kandung berkebutuhan khusus dan tinggal satu rumah dengan adiknya. Temuan penelitian ini adalah komunikasi interpersonal masih terjalin, komunikasi dilakukan dengan tatap muka tanpa medium, bentuk komunikasi kakak menyesuaikan kebutuhan adik, bentuk komunikasi adik umumnya berbentuk nonverbal, setiap informan mengalami dialektika relasional, dan pertukaran kasih sayang masih mungkin terjadi.

Kata Kunci: dialektika relasional, kebutuhan khusus, komunikasi interpersonal, penyandang autisme 


\section{Pendahuluan}

Pada dasarnya, setiap keluarga berharap memiliki anggota keluarga yang sempurna, sehat secara jasmani maupun rohani, hingga perkembangan fisik dan akal pikiran yang sesuai dengan usianya (Adewiyah, 2014). Hal ini tidak semata-mata hanya harapan dari orang tua saja, melainkan pengharapan setiap anak untuk memiliki saudara kandung yang sempurna serta sehat secara jasmani dan rohani agar terciptanya interaksi yang dekat antar saudara seperti saling berbagi dan bermain bersama (Meilisa, 2015). Namun pada kenyataannya terdapat beberapa keluarga dianugerahi anggota keluarga dengan perhatian khusus atau biasanya dikenal juga dengan sebutan individu dengan kebutuhan khusus.

Menurut Peraturan Menteri Pemberdayaan Perempuan dan Perlindungan Anak Republik Indonesia, Nomor 10 tahun 2011 tentang Kebijakan Penanganan Anak Berkebutuhan Khusus, individu berkebutuhan khusus terbagi menjadi 12 (dua belas) kategori, salah satu diantaranya yaitu individu yang menyandang autisme atau Autism Spectrum Disorder (ASD) (Kemen PPPA, 2018). Monks menuliskan bahwa jika ditinjau dari asal bahasanya, autisme terdiri dari kata "autos" yang memiliki arti "sendiri”. Para penyandang autisme dikenal sulit melakukan kegiatan komunikasi dan interaksi dengan lingkungan sekitarnya (Safitri, 2016). Selain itu, penyandang autisme juga cenderung lebih suka menyendiri dibandingkan bersosialisasi dengan orang lain maupun dengan keluarganya sendiri (Aulia, Ardipal, dan Yuliasma, 2014). Tidak jarang pula maksud dan keinginan para penyandang autisme tidak tersampaikan dengan baik atau bahkan disalah pahami (Rahayu, 2014). Hal tersebut dapat terjadi karena mereka tidak dapat mengekspresikan emosi serta perasaannya dengan baik (Mahardani, 2016).

Seorang pakar psikologi komunikasi yang bernama Paul Watzlawick pernah mengatakan "We cannot not communicate" yang artinya kita tidak bisa tidak berkomunikasi dikarenakan manusia menjadikan komunikasi sebagai kebutuhan dasar (Nurudin, 2017). Mulyana dalam bukunya menambahkan pernyataan bahwa setiap detik manusia melakukan kegiatan serta cara berkomunikasi yang baik dalam berbagai konteks komunikasi seperti komunikasi antarpribadi, komunikasi kelompok, komunikasi organisasi, komunikasi massa, dan lain sebagainya (Mulyana, 2013).

Pernyataan-pernyataan di atas tidak menunjukkan adanya pengecualian kebutuhan komunikasi pada individu yang berkebutuhan khusus. Namun orang-orang yang berada di sekitar lingkungan individu dengan kebutuhan khusus diharapkan dapat lebih sabar dalam menjalin komunikasi dengan individu tersebut. Karena pada dasarnya sebagian besar individu dengan kebutuhan khusus dalam level tertentu masih dapat melakukan kegiatan komunikasi dan membutuhkan komunikasi untuk menyampaikan apa yang diinginkan atau dimaksudkan, walau tidak jarang pula sulit dimengerti oleh orang lain.

Jika ditinjau lebih dalam lagi, permasalahan tidak hanya terletak pada diri individu dengan kebutuhan khusus, namun juga memberikan dampak pada keluarga. Individu yang memiliki saudara kandung dengan kebutuhan khusus akan mengalami stres sosial terkait dengan keterbatasan dalam diri saudaranya. Semakin tinggi level keparahan yang dialami oleh individu berkebutuhan khusus maka akan sebanding pula dengan semakin tinggi tingkat stres sosial yang akan dialami (Cynthia, 2014).

Pada kasus kakak yang memiliki adik kandung berkebutuhan khusus, seorang kakak lebih banyak berperan dalam mempertahankan relasi antar saudara dan seharusnya dapat memahami keberadaan adiknya serta tetap menjalankan perannya 
Jessica Laurance, Riris Loisa: Komunikasi Interpersonal Antara Kakak dengan Adik Kandung Berkebutuhan Khusus (Studi Kasus pada Kakak yang Mempunyai Adik Kandung Penyandang Autisme)

sebagai seorang kakak. Relasi antar saudara merupakan relasi yang istimewa dan paling bertahan lama dalam kehidupan manusia (Cicirelli, dalam Kuo, Orsmond, Seltzer, 2009). Saudara kandung juga dinilai dapat memberikan pengaruh sosial yang lebih besar dari orang tua karena dengan jarak usia yang dekat maka saudara kandung dapat lebih memahami permasalahan yang dihadapi saudaranya dan berkomunikasi lebih efektif (Nurmaningtyas, dalam Asteria, 2016).

Dalam penelitian ini, yang menjadi fokus peneliti adalah komunikasi interpersonal. Peneliti memilih topik dan fokus penelitian dikarenakan salah satu cara mempertahankan relasi antar saudara adalah dengan melakukan komunikasi antarpribadi. Dengan demikian, maka permasalahan yang akan dibahas adalah bagaimana komunikasi interpersonal yang terjalin antara kakak dengan adik kandung berkebutuhan khusus.

\section{Metode Penelitian}

Pendekatan penelitian yang digunakan oleh peneliti adalah kualitatif yang bersifat deskriptif. Denzin dan Lincoln (2009) berpendapat bahwa pendekatan kualitatif adalah suatu proses penelitian dan pemahaman yang berdasarkan pada metodologi untuk menyelidiki suatu fenomena sosial dan masalah manusia serta menekankan sifat realitas yang terbangun secara sosial, hubungan erat antara peneliti dengan subjek yang diteliti (Noor, 2017). Sementara pengertian metode deskriptif menurut Nazir (2011) adalah suatu metode dalam meneliti status kelompok manusia, suatu objek, suatu set kondisi, suatu sistem pemikiran, maupun suatu kelas peristiwa pada masa sekarang.

Metode yang digunakan peneliti dalam penelitian ini adalah studi kasus Sujarweni (2014) menjelaskan bahwa studi kasus merupakan penelitian mengenai manusia (dapat suatu kelompok, organisasi, maupun individu), peristiwa, latar secara mendalam, tujuan dari penelitian ini mendapatkan gambaran yang mendalam tentang suatu kasus yang sedang diteliti. Ciri khas dari metode studi kasus adalah adanya "sistem yang terbatas" (bounded system) atau adanya batasan dalam hal waktu dan tempat serta batasan dalam hal kasus yang diangkat. Kasus-kasus yang diangkat dapat berupa program, kejadian, aktivitas, maupun subyek penelitian (Herdiansyah, 2014).

Teknik pengumpulan data yang digunakan oleh peneliti meliputi wawancara mendalam, observasi, dokumentasi, studi kepustakaan, dan penelusuran data online. Setelah pengumpulan data selesai dilakukan, langkah berikutnya peneliti menggunakan pengodean untuk menganalisis data. Menurut Strauss dan Corbin (1990), analisis data kualitatif terdiri atas tiga jenis pengodean (coding) utama, yaitu:

(1) Pengodean Terbuka (Open Coding), (2) Pengodean Berporos (Axial Coding), dan (3) Pengodean Selektif (Selective Coding) (Emzir, 2012).

\section{Hasil Temuan dan Diskusi}

Hasil temuan dan diskusi dalam penelitian ini akan peneliti jabarkan dalam beberapa sub-pembahasan, yakni:

\section{Medium Komunikasi Interpersonal Antara Kakak dengan Adik Kandung Berkebutuhan Khusus}

Komunikasi interpersonal dapat dilakukan secara tatap muka dengan medium maupun tanpa medium (Susanto, 2018). Berdasarkan hasil jawaban ketiga informan, 
peneliti menemukan kesamaan medium utama yang digunakan oleh para informan, yaitu komunikasi secara langsung dalam tatap muka tanpa medium. Hal ini sesuai dengan pengertian komunikasi antarpribadi yang dikemukakan oleh Susanto (2018).

Alasan yang diutarakan oleh Informan 1 yaitu dikarenakan sang adik terkadang kurang mengerti dan memahami pembicaraan jika menggunakan medium telepon, sedangkan Informan 2 mengatakan ia dapat meminta adiknya untuk melakukan kontak mata ketika komunikasi secara tatap muka dengan tujuan agar sang adik dapat mengerti apa yang sedang disampaikan. Terdapat sebuah kesamaan dari kedua alasan informan, yaitu agar sang adik dapat lebih mudah mengerti dan memahami apa yang disampaikan kakaknya. Pernyataan Informan 1 juga sesuai dengan hasil observasi peneliti, yakni ketika informan melakukan video call dengan adiknya di sela-sela wawancara, sang adik kurang dapat merespons dengan baik pertanyaan yang ditanyakan oleh informan.

Di sisi lain, Ibu Mellisa Florentina selaku key informant penelitian ini juga membenarkan bahwa komunikasi tatap muka merupakan komunikasi yang lebih efektif dan memuaskan. Beliau mengatakan selain untuk mendapatkan feedback secara langsung, berbicara dengan anak berkebutuhan khusus juga sedikit berbeda dikarenakan memerlukan pendekatan, penyesuaian, hingga perhatian yang lebih.

\section{Komunikasi Interpersonal Sebagai Pemenuhan Kebutuhan Antarpersonal}

Sebagai pengantar, peneliti menanyakan apakah informan merasa perlu untuk melakukan komunikasi antarpribadi dengan adik. Informan 1 dan 3 menyatakan bahwa komunikasi perlu dilakukan dengan tujuan memenuhi hubungan primordial. Sementara Informan 2 mengutarakan latar belakang ia merasa perlu melakukan komunikasi dengan adiknya sebagai bentuk kontrol dirinya terhadap sang adik.

Untuk mengetahui lebih lanjut tujuan dari komunikasi antarpribadi antara kakak dengan adiknya, peneliti menanyakan beberapa pertanyaan yang sama kepada ketiga informan. Dengan jawaban dari para informan, peneliti mendapati bahwa setiap informan menjalankan komunikasi antarpribadi dengan adiknya untuk memenuhi kebutuhan inklusi, kontrol, serta afeksi, sebagaimana yang dijelaskan dalam teori FIRO (Fundamental Interpersonal Relationships Orientations). Namun pada beberapa kondisi, tujuan dilakukan komunikasi juga untuk memenuhi tanggung jawab informan sebagai seorang kakak. Selain itu, pertukaran kasih sayang juga masih memungkinkan terjadi walaupun pada dua kasus dalam penelitian ini sang adik harus diberikan stimulus terlebih dahulu, sedangkan pada satu kasus yang lainnya merupakan inisiatif dalam diri sang adik untuk melakukan pertukaran kasih sayang terhadap kakaknya.

\section{Pola Interaksi Kakak dengan Adik Kandung Berkebutuhan Khusus}

Berdasarkan hasil wawancara peneliti dengan informan menunjukkan bahwa Informan 1 dan 2 memiliki pola interaksi hubungan antarpribadi yang cukup konsisten dengan adiknya. Hal ini dikarenakan Informan 1 melakukan komunikasi dengan adiknya pada saat sebelum berangkat dan sepulang kerja, selain itu juga ia melakukan komunikasi ketika sedang waktu libur. Di sisi lain, Informan 2 menyatakan bahwa ia lebih sering melakukan komunikasi ketika hari libur seperti Sabtu dan Minggu. Berbeda dengan kedua informan lainnya, Informan 3 dalam wawancara menyatakan bahwa dirinya berkomunikasi dengan adiknya ketika ia sedang ingin berinteraksi saja, akan tetapi ia tidak melakukan pembatasan diri untuk berkomunikasi dengan adiknya. 
Jessica Laurance, Riris Loisa: Komunikasi Interpersonal Antara Kakak dengan Adik Kandung Berkebutuhan Khusus (Studi Kasus pada Kakak yang Mempunyai Adik Kandung Penyandang Autisme)

Dengan pola interaksi yang tidak teratur maka tentu saja dapat memengaruhi fungsi komunikasi antarpribadi. Di sisi lain, peneliti juga menemukan bahwa fungsi komunikasi antarpribadi pada beberapa kondisi dapat diabaikan apabila ada hal lain yang lebih mendesak. Contohnya adalah ketika hari kerja, karena masing-masing informan harus berangkat kerja di pagi hari dan pulang kerja pada malam hari.

\section{Hambatan dalam Meningkatkan Hubungan Insani Antara Kakak dengan Adik Kandung Berkebutuhan Khusus}

Dengan segala keterbatasan individu dengan sindrom autis, maka hal tersebut secara tidak langsung menjadi hambatan dalam meningkatkan hubungan insani antar saudara. Pernyataan ini dirasakan langsung oleh para informan dalam penelitian ini dan mereka mengaku bahwa keterbatasan sang adik menjadi faktor utama yang menghambat komunikasi antarpribadi antara diri mereka dengan adiknya. Hambatan yang dirasakan juga berbeda antara informan satu dengan yang lainnya.

Informan 1 merasa yang menjadi hambatan komunikasi antara ia dengan adiknya adalah komunikasi yang masih satu arah sampai saat ini dan keterbatasan kemampuan dalam merangkai kalimat, walaupun sebenarnya sang adik dapat memberikan tanggapan atau jawaban ketika diajukan pertanyaan. Di sisi lain, Informan 2 mengutarakan alasan yang lebih sederhana, yaitu kesulitan sang adik diajak berbincang sehingga ia akan merasa tidak puas ketika mengajak adiknya berkomunikasi dikarenakan kesulitan tersebut.

Sementara di sisi Informan 3, yang menjadi hambatan dalam berkomunikasi dengan adiknya yaitu kemampuan berbahasa sang adik, seperti kosakata yang terbatas serta pemahaman mengenai suatu kata yang kurang. Di samping perbedaan hambatan yang dialami, ada kesamaan dalam pernyataan yang diutarakan oleh Informan 3 dan 1, yakni pembahasan yang dapat dibicarakan dengan adik masing-masing tidak dapat berupa topik yang berat atau abstrak. Penggunaan kata tanya Bagaimana dan Mengapa akan membuat adiknya bingung untuk menjawab pertanyaan yang dilontarkan, atau bahkan kerap kali sang adik akan membuat konkret sebuah pertanyaan atau jawaban yang abstrak. Kata tanya yang mudah diterima oleh adiknya, yaitu seperti kata tanya Apa, Siapa, dan Kapan.

\section{Terjadinya Konflik Dalam Hubungan Antarpribadi Kakak dengan Adik Kandung Berkebutuhan Khusus}

Salah satu fungsi komunikasi antarpribadi yaitu menghindari dan mengatasi konflik pribadi. Menurut pengakuan para informan, mereka pernah mengalami konflik dengan adiknya masing-masing. Konflik yang dialami Informan 1 berupa tingkah laku adik yang mengganggu, langkah yang diambil oleh Informan 1 untuk mengatasi konflik yang ada yaitu tidak terlalu mengambil hati ketika terjadi konflik dan berusaha untuk mengerti keterbatasan sang adik.

Keadaan serupa juga dinyatakan oleh Informan 2, ia mengatakan bahwa terjadinya konflik umumnya diakibatkan kesalahan yang diperbuat oleh sang adik. Berbeda dengan Informan 1, Informan 2 mengaku walau awalnya memarahi sang adik, ia akan segera mengajak adiknya bercanda atau memberikan elusan saat suasana hati adiknya sudah membaik. Sementara pada sisi lain, Informan 3 mengalami konflik ketika adiknya tidak dapat mengerti apa yang dimaksudkan oleh sang kakak. Hal tersebut dikarenakan harapan tidak sesuai dengan kenyataan yang terjadi atau sang adik tidak bertindak selayaknya anak seusianya. Namun walaupun faktor terjadinya 
konflik berbeda, tindakan yang dilakukan oleh Informan 3 menyerupai langkah yang diambil oleh Informan 1, yaitu dengan mengalah dan mengerti keterbatasan adiknya.

\section{Aktivitas Komunikasi Interpersonal Antara Kakak dengan Adik Kandung Berkebutuhan Khusus}

Pesan verbal merupakan semua jenis simbol yang menggunakan satu atau bahkan lebih dari satu kata (Mubarok dan Andjani, 2014). Sedangkan pesan nonverbal meliputi kinesik, paralanguage, proksemik, wilayah, artefak, penampilan diri, penggunaan waktu, dan komunikasi pencium (Budyatna, \& Ganiem, 2012). Berdasarkan hasil wawancara, peneliti mendapati bahwa penggunaan pesan tiap informan berbeda-beda. Informan 2 mengatakan ia lebih banyak menggunakan pesan verbal, sedangkan Informan 3 lebih banyak menggunakan pesan nonverbal. Sementara di sisi lain, Informan 1 mengaku bahwa penggunaan pesan verbal dan nonverbal seimbang dalam komunikasi dengan adiknya. Perbedaan penggunaan pesan tersebut dikarenakan penyesuaian terhadap kebutuhan adik dari masing-masing informan. Masing-masing informan juga menegaskan bahwa pemilihan penggunaan pesan merupakan bentuk komunikasi yang paling efektif di antara dirinya dan adiknya.

Komunikasi verbal yang digunakan oleh para informan berbentuk kata-kata secara ucapan lisan. Dan umumnya komunikasi verbal yang diucapkan berupa pertanyaan, bukan pernyataan. Pertanyaan-pertanyaan yang diajukan oleh para informan kepada adiknya bersifat konkret dan jawabannya tidak membutuhkan pemikiran yang kritis. Hal ini sesuai dengan hasil observasi peneliti terhadap adik informan. Pada saat observasi, peneliti selalu melakukan interaksi dengan adik para informan. Melalui interaksi tersebut, peneliti mencoba menanyakan beberapa pertanyaan pada adik informan, namun yang dapat dijawab memang hanya pertanyaan yang lebih mudah dicerna saja.

Sementara itu, bentuk komunikasi nonverbal yang digunakan oleh informan berkenaan dengan kinesik, atau biasa disebut juga dengan gerakan tubuh yang meliputi kontak mata, ekspresi wajah, gerak-isyarat, postur atau perawakan, dan sentuhan (Budyatna dan Ganiem, 2012). Selain itu, peneliti menemukan kesamaan cara komunikasi dari adik ke kakak yaitu penggunaan pesan nonverbal sebagai cara untuk berkomunikasi atau menunjukkan apa yang ingin disampaikan dan dirasakan. Berdasarkan hasil observasi peneliti, ketiga adik informan sebenarnya masih dapat melakukan komunikasi, hanya saja memang keterbatasan mereka dalam melakukan komunikasi sosial membuat mereka seakan lebih baik menunjukkannya dengan pesan nonverbal dibanding mengutarakan jawabannya secara pesan verbal.

\section{Pengalaman Dialektika Relasional pada Kakak yang Memiliki Adik Kandung Berkebutuhan Khusus}

Dialektika relasional ditandai dengan adanya dorongan dan tarikan dari keinginan yang bertolak belakang di dalam seluruh bagian hidup berhubungan dengan orang lain. Salah satu asumsi dalam teori dialektika relasional menyatakan bahwa komunikasi merupakan hal yang penting dalam mengelola maupun menegosisasi kontradiksi yang terdapat pada suatu hubungan (West \& Turner, 2009). Menurut Ibu Mellisa, dialektika merupakan hal yang wajar terjadi dan diperlukan dalam kehidupan manusia karena hubungan dengan manusia tidak linier. Selain itu, beliau juga menyatakan dengan adanya dialektika dalam sebuah hubungan dapat menimbulkan dua kemungkinan, yaitu perkembangan atau penurunan suatu hubungan. 
Jessica Laurance, Riris Loisa: Komunikasi Interpersonal Antara Kakak dengan Adik Kandung Berkebutuhan Khusus (Studi Kasus pada Kakak yang Mempunyai Adik Kandung Penyandang Autisme)

Untuk menggambarkan dialektika relasional yang terjadi dan dirasakan, peneliti menanyakan apakah informan pernah merasa tidak nyaman ketika tidak berinteraksi dengan adiknya. Berdasarkan jawaban dari para informan, peneliti menilai ketiga informan pernah mengalami dialektika relasional. Dialektika relasional yang terjadi pada masing-masing informan disebabkan oleh keterbatasan sang adik. Setiap informan merasa tidak perlu larut terlalu dalam pada kondisi tersebut dan mengambil langkah untuk menerima keterbatasan sang adik. Walaupun sudah bisa menerima kekurangan adik, Informan 2 mengaku masih dapat tetap merasakan dialektika, terutama ketika suasana hatinya kurang baik. Di sisi lain, Informan 1 juga masih dapat merasakan dialektika namun masih dapat dikendalikan oleh dirinya. Sementara Informan 3 menyatakan bahwa dirinya sudah cukup dapat menerima kondisi adiknya.

\section{Simpulan}

Berdasarkan hasil temuan dan diskusi di atas, maka dapat ditarik kesimpulan bahwa komunikasi interpersonal antara kakak dengan adik kandung berkebutuhan khusus masih terjalin dan dilakukan secara tatap muka tanpa medium. Bentuk komunikasi tatap muka kakak terhadap adik disesuaikan dengan kebutuhan sang adik. Dalam artian jika adiknya lebih mudah memahami pesan secara verbal maka komunikasi yang lebih banyak digunakan yaitu komunikasi verbal, dan begitu pula sebaliknya. Sedangkan apabila pemahaman sang adik terhadap pesan verbal dan nonverbal kurang baik, maka bentuk komunikasi yang digunakan harus seimbang antara verbal dengan nonverbal.

Selain itu, dalam penelitian ini peneliti juga menemukan bahwa seorang kakak yang mempunyai adik kandung berkebutuhan khusus pasti pernah mengalami dialektika relasional dalam hidupnya. Dialektika relasional yang dirasakan dapat diatasi dengan baik oleh masing-masing individu, walaupun terkadang kontradiksi masih dapat muncul pada beberapa waktu. Dengan segala kondisi yang ada, pertukaran kasih sayang masih mungkin terjadi, walaupun pada dua kasus hanya dapat dilakukan dengan adanya stimulus dari kakak, sedangkan pada satu kasus lainnya merupakan inisiatif dari dalam diri adik tanpa stimulus dari siapapun.

\section{Ucapan Terima Kasih}

Ucapan terima kasih peneliti berikan kepada Mutiara Kinanti, Martha Paramitha Maeliva, dan Jonathan Ferro sebagai informan, serta Ibu Mellisa Florentina selaku key informant yang telah bersedia meluangkan waktu dan memberikan informasi kepada peneliti selama proses pengumpulan data dalam penelitian ini. Peneliti juga mengucapkan terima kasih kepada seluruh pihak yang tidak dapat disebutkan satu per satu yang telah membantu dan mendukung peneliti dalam proses penyusunan skripsi.

\section{Daftar Pustaka}

Adewiyah, Rofiana. (2014). Pengalaman Komunikasi Antarpribadi Ibu dari Anak Penyandang Autis di Lingkungan Keluarga (Studi Pada Ibu yang Memiliki Anak Autis yang Bersekolah di Sekolah Luar Biasa River Kids Malang). Skripsi Jurusan Ilmu Komunikasi Fakultas Ilmu Sosial Dan Ilmu Politik Universitas Muhammadiyah Malang. Agustus 20, 2019. Terarsip di: http://eprints.umm.ac.id/26542/ 
Asteria, Dwi Fani. (2016). Studi Fenomenologi: Pengalaman Saudara Kandung Yang Memiliki Anggota Keluarga Dengan Autis di SLB Autis YPPA Padang Tahun 2016. E-Skripsi Universitas Andalas. Oktober 19, 2019. Terarsip di: http://scholar.unand.ac.id/17739/

Aulia, Sri M., Ardipal, Yuliasma. (2014). Pembelajaran Pola Ritem Untuk Anak Berkebutuhan Khusus (Autis) Dengan Media Warna. E-Jurnal Sendra Tasik, 2 (2). Oktober 18, 2019. Terarsip di: http://ejournal.unp.ac.id/index.php/sendratasik/article/view/3124/2624

Budyatna, Muhammad., \& Ganiem, Leila Mona. (2012). Teori Komunikasi Antarpribadi. Jakarta: Prenada Media Group.

Cynthia, Rebecca Stephanie. (2014). Gambaran Strategi Pengelolahan Stres Sosial Pada Remaja Yang Memiliki Adik Kandung Dengan Autisme. Skripsi Fakultas Psikologi Universitas Airlangga Surabaya. Oktober 19, 2019. Terarsip di: https://www.academia.edu/13087496/Strategi_Coping_Stres

Emzir. (2012). Analisis Data: Metodologi Penelitian Kualitatif (ed. 1-3). Jakarta: Rajawali Pers.

Herdiansyah, Haris. (2014). Metodologi Penelitian Kualitatif untuk Ilmu-ilmu Sosial. Jakarta: Salemba Humanika.

Kemen PPPA. (2018). Membangun Masa Depan Anak Berkebutuhan Khusus. Oktober 19, 2019. Terarsip di https://www.kemenpppa.go.id/index.php/page/read/31/1621/membangunmasa-depan-anak-berkebutuhan-khusus

Mahardani, Dhiki Yulia. (2016). Kemampuan Komunikasi Dalam Berinteraksi Sosial Anak Autis di Sekolah Dasar Negeri Bangunrejo 2. Skripsi Program Studi Pendidikan Luar Biasa Jurusan Pendidikan Luar Biasa Fakultas Ilmu Pendidikan Universitas Negeri Yogyakarta. Oktober 18, 2019. Terarsip di: https://eprints.uny.ac.id/40964/1/DHIKI\%20YULIA\%20MAHARDANI_121 03244061.pdf

Meilisa, Mira. (2015). Sibling Relationship Pada Remaja Akhir Dengan Saudara Yang Berkebutuhan Khusus. Skripsi Fakultas Psikologi Universitas Medan Area. Oktober 18, 2019. Terarsip di: http://repository.uma.ac.id/handle/123456789/1571

Mubarok, \& Andjani, Made D. (2014). Komunikasi Antarpribadi Dalam Masyarakat Majemuk. Jakarta: Dapur Buku.

Mulyana, Deddy. (2013). Ilmu Komunikasi Suatu Pengantar. Bandung: PT Remaja Rosdakarya.

Nazir. (2011). Metode Penelitian. Bogor: Ghalia Indonesia.

Noor, Juliansyah. (2017). Metodologi Penelitian: Skripsi, Tesis, Disertasi, dan Karya Ilmiah (ed. 1). Jakarta: Kencana.

Nurudin. (2017). Ilmu Komunikasi Ilmiah dan Populer. Depok: Rajawali Pers.

Orsmond, G.I., Kuo, H.Y., \& Seltzer, M.M. (2009). Siblings of Individuals with An Autism Spectrum Disorder: Sibling Relationships and Wellbeing in Adolescence and Adulthood. Autism, 13 (1), 59-80. Oktober 18, 2019. Terarsip di: https://www.ncbi.nlm.nih.gov/pmc/articles/PMC2651641/

Safitri, Yulia Nanda. (2016). Penerimaan Diri Seorang Ayah yang Memiliki Anak Autisme. Skripsi Fakultas Psikologi Universitas Medan Area. Oktober 18, $2019 . \quad$ Terarsip di: http://repository.uma.ac.id:8081/handle/123456789/240?mode=full 
Jessica Laurance, Riris Loisa: Komunikasi Interpersonal Antara Kakak dengan Adik Kandung Berkebutuhan Khusus (Studi Kasus pada Kakak yang Mempunyai Adik Kandung Penyandang Autisme)

Sujarweni, V. Wiratna. (2014). Metodologi Penelitian. Yogyakarta: Pustaka Baru Press.

Susanto, Eko Harry. (2018). Komunikasi Manusia: Teori dan Praktek Dalam Penyampaian Gagasan. Jakarta: Mitra Wacana Media.

West, R., \& Turner, Lynn H. (2009). Pengantar Teori Komunikasi: Analisis dan Aplikasi. Jakarta: Salemba Humanika. 